\title{
(2) OPEN ACCESS
}

\section{Identifying a gap in drowning prevention: high- risk populations}

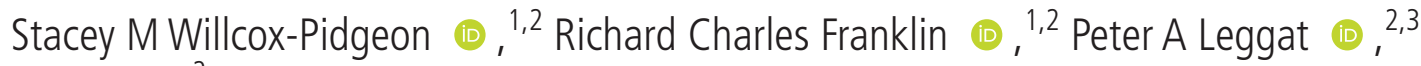 \\ Sue Devine ${ }^{2}$
}

- Additional material is published online only. To view, please visit the journal online (http://dx.doi.org/10.1136/ injuryprev-2019-043432).

${ }^{1}$ Royal Life Saving Society Australia, Broadway, New South Wales, Australia

${ }^{2}$ College of Public Health, Medical and Veterinary Sciences, James Cook University, Townsville, Queensland, Australia

${ }^{3}$ School of Medicine, College of Medicine, Nursing and Health Sciences, National University of Ireland, Galway, Ireland

\section{Correspondence to}

Stacey M Willcox-Pidgeon, Royal Life Saving Society Australia, Broadway, New South Wales, Australia; spidgeon@rlssa. org.au

Received 11 August 2019 Revised 19 November 2019 Accepted 24 November 2019 Published Online First 6 January 2020

\section{Check for updates}

(C) Author(s) (or their employer(s)) 2020. Re-use permitted under CC BY-NC. No commercial re-use. See rights and permissions. Published by BMJ.

To cite: Willcox-Pidgeon SM, Franklin RC, Leggat PA, et al. Inj Prev 2020;26:279-288.

\begin{abstract}
Introduction Some populations have been less susceptible to reductions in drowning than others. It has been hypothesised that this is due to prevention strategies failing to account for the influence of social determinants (such as ethnicity, socioeconomic status). Populations such as ethnic minorities have been overrepresented in injury statistics, however this is not well explored in drowning. This study aims to identify highrisk populations for drowning, risk factors and prevention strategies.
\end{abstract}

Methods A literature review undertaken systematically using the Preferred Reporting Items for Systematic Reviews and Meta-Analyses approach was conducted of peer-reviewed literature in English, published between 1990 and 2018 from high-income countries. Search terms included drowning, water safety, ethnic minority, migrant, and culturally diverse.

Results In total, 35 articles were included. High-risk populations identified were: ethnic minorities, First Nations/Aboriginal people, migrants and rural residents. Over half (51\%) focused on children (0-18 years). Risk factors included social determinants, swimming ability and knowledge, attitudes and behaviour. Four intervention studies were found; two focused on upskilling adults from high-risk populations to increase employment opportunities within the aquatic industry; an evaluation of a 10-year rock fishing safety education project and a learn-to-swim programme for minority children. Proposed prevention strategies included education, practical skills, research, policy and engagement.

Discussion Limited literature exists pertaining to drowning among adults from high-risk populations. There is a need to increase the sophistication of drowning prevention strategies addressing the disparities in drowning from a culturally appropriate perspective. Acknowledging the role of the social determinants of health in drowning prevention is essential in order to improve drowning outcomes for high-risk populations globally.

\section{INTRODUCTION}

The leading causes of unintentional fatal injury deaths are road traffic, falls and drowning. ${ }^{1}$ In order to significantly improve injury mortality and morbidity rates worldwide, a greater knowledge of the factors that cause or contribute to these issues is required to enhance understanding and effectiveness of injury prevention interventions. At the population and community level, public health strategies and injury prevention interventions often fail to account for the broader social, cultural and environmental determinants that influence health outcomes; however, they are key when aiming to influence behaviour and understanding the challenges in doing so. The social determinants of health, as defined by WHO, are:

The conditions in which people are born, grow, work, live, and age, and the wider set of forces and systems shaping the conditions of daily life. These forces and systems include economic policies and systems, development agendas, social norms, social policies and political systems. ${ }^{2}$

Traditionally, the social determinants of health include gender, income and employment, education, housing and social support. ${ }^{23}$ It is well-known that the individual determinants of ethnicity, race and cultural background are intertwined into social norms, policies and political systems that influence health outcomes, thus creating inequities. Worldwide, poor health outcomes are influenced by intergenerational trauma (eg, colonisation), poverty and institutional racism, which are directly related to a person's race and ethnicity. ${ }^{34}$ Minority populations worldwide have poor injury-related morbidity and mortality outcomes. For example, in London 'black' children were found to have higher rates of pedestrian injuries compared with others, ${ }^{5}$ and in Arizona, American Indians were reported as having a higher RR of death from MVCs compared with people of other ethnic backgrounds. ${ }^{6}$

Reducing the number of drowning-related deaths would greatly contribute to decreasing the number of premature, preventable injury-related deaths, particularly among young children (0-4 years). Globally, an estimated 360000 drowning deaths occur annually worldwide, with lowincome and middle-income countries, children and males accounting for the highest burden.? WHO suggests that populations at elevated risk of drowning include those of socioeconomic status, with poor levels of education, people living in rural and remote settings and ethnic-minority populations (both in high-income and low-income countries). ${ }^{7}$ For example, black, Hispanic and Latino populations are reported to have the highest rates of drowning in the USA, ${ }^{89}$ and in New Zealand, people of Maori and Pacific Islander ethnicity record higher drowning rates compared with the European population, ${ }^{10}$ and Aboriginal people are over-represented in the drowning statistics in Canada. $^{4}$

Well-known factors that influence drowning risk include age, gender, environmental context, activity 
and alcohol consumption ${ }^{7}$; however, less is known about the contributing factors for drowning within specific groups deemed at higher risk of drowning, such as ethnic-minority populations.

In Australia, high-risk populations are recognised as a priority area for reducing drowning. ${ }^{11}$ In the Australian context this refers to populations that record high rates of drowning when adjusted by the general population (per 100000 ), or people who may have less access to swimming and water safety education for a variety of reasons. ${ }^{11}$ Such populations identified include First Nations Australians (referred to hereafter as Aboriginal and Torres Strait Islander peoples), culturally diverse communities, international students and international tourists. Of the 280 people that drown on average annually in Australia, approximately 72 people are from these high-risk populations. ${ }^{11}$

The terms ethnicity and race are used interchangeably depending on context (eg, Government documents, nongovernment organisations and literature); however, they do have slightly different meanings. The term ethnicity recognises shared cultural, religious and language factors that may need to be considered when working with culturally diverse populations. ${ }^{12}{ }^{13}$ For the purpose of this study, the term ethnicity refers to:

The social group a person belongs to, and either identifies with or is identified with by others, as a result of a mix of cultural and other factors including language, diet, religion, ancestry, and physical features $^{12}$ (p. 443).

Whereas, a person's race is generally based on the:

Historical and common usage the group (sub-species in traditional scientific use) a person belongs to as a result of a mix of physical features such as skin colour and hair texture, which reflect ancestry and geographical origins ${ }^{12}$ (p. 444).

Similarly, the term migrants and immigrants are used interchangeably, depending on country and context. For the purposes of this study, the authors have chosen to use the The International Organization for Migration's broad terminology to describe a migrant ${ }^{14}$ :

A person who moves away from his or her place of usual residence, whether within a country or across an international border, temporarily or permanently, and for a variety of reasons. The term includes a number of well-defined legal categories of people, such as migrant workers; persons whose particular types of movements are legally defined, such as smuggled migrants; as well as those whose status or means of movement are not specifically defined under international law, such as international students ${ }^{14}$ (p. 130).

An abundance of literature exists on drowning prevention for young children ${ }^{1516}$ and a few drowning-related studies have investigated males. ${ }^{17} 18$ Other populations considered high risk for drowning, such as ethnic-minority populations, including Indigenous peoples, have not received the same attention.

The aims of this study were to:

- To identify research pertaining to drowning statistics, focusing on ethnic-minority populations.

- To examine the contributing factors for drowning among the identified high-risk populations, focusing on the broader social and health influences.

- To explore knowledge gaps in drowning prevention strategies for the identified populations.

\section{METHODS}

A scoping literature review was conducted systematically to identify relevant research using a modified Preferred Reporting Items for Systematic Reviews and Meta-Analyses (PRISMA) methodology. Key databases searched were: Medline, PyschInfo, SCOPUS, Web of Science, Cochrane Library and SafetyLit. Search terms included: drown", swim", "water safety", "injury" AND 'ethnic", 'migrant', 'minority', 'cultur"', 'diverse', 'vulnerable'. Search limitations included original peer-reviewed articles in English, published between 1990 and 2018 from high-income countries. Systematic reviews, published conference papers and grey literature were excluded. Hand searching of the reference lists of the included articles were also undertaken. The authors worked with a librarian to conduct a sample search to ensure that the key search terms, including MeSH terms, covered the range of studies being investigated.

Articles were assessed using the following criteria: (1) drowning risk, swimming ability or water safety was the main focus of the study, (2) the target population was identified as being at increased risk of drowning, (3) ethnicity/race was a key outcome and (4) risk factors mentioned determinants of health, such as socioeconomic status.

Exclusion criteria included: (1) intentional self-harm or violence, (2) swimming sports, not related to drowning, (3) health and injury epidemiology studies where drowning was not the primary outcome, (4) aquatic-related injury and fatalities excluding drowning, (5) drowning studies without reference to ethnicity/race, (6) studies pertaining to tourists. The reason for excluding tourists was due to being a transient population, and the difficulty in evaluating the effectiveness of strategies to either reduce drowning deaths, or that increase awareness and knowledge.

To assess the methodological quality of studies, the McMaster University critical review tools (qualitative and quantitative) were used to appraise articles. ${ }^{19}{ }^{20} \mathrm{~A}$ range of study designs were included to ensure that all relevant original literature was captured. As this was not a systematic review, rather a scoping review, the aim was to collect as much published literature as possible. The authors expected that little literature may have been available and of varying quality and methodological strength. For the purpose of this review, epidemiological studies were considered a subset of quantitative studies that presented population-level large-scale data, for example, hospitalisation, death data or population statistics, to separate out from smaller studies, for example, cross-sectional surveys.

Database searching by the primary author (SMW-P) initially resulted in 939 articles. After removing duplicates, a title and keyword search was undertaken against the inclusion/exclusion criteria. Abstract screening resulted in 145 articles (figure 1). Full-text screening resulted in 100 articles being removed due to not meeting the study inclusion criteria. A final screening of the remaining articles by the both the first (SMW-P) and second author (RCF) was conducted against the criteria, in which 10 articles were removed for two reasons: (1) the study was conducted in a low-income country setting or (2) a narrative review or commentary, not original research resulting in 35 articles included in this review (figure 1). Aggregated results of the studies will be presented in the 'Results' section. Descriptive statistics and thematic analysis ${ }^{21}$ were used to analyse the results. For individual synthesis of each article, and included data extracted, refer to online supplementary file 1.

\section{RESULTS}

Thirty-five articles were included in this review. See online supplementary file 1 for a summary of articles reviewed. Of the 35 articles, 25 were quantitative studies, of which 10 were epidemiological studies, 9 qualitative studies (mix of study designs) 


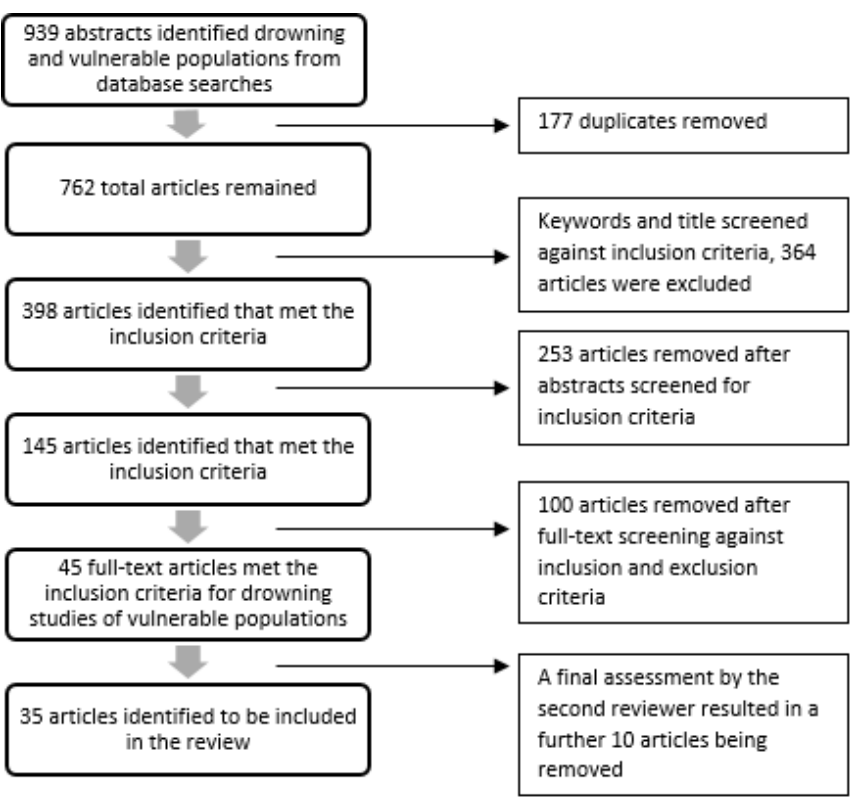

Figure 1 Modified PRISMA process.

and 1 was a mixed-methods study. Twenty studies were from the USA, with the remaining studies from New Zealand, Australia and Canada (table 1). Sample size of participants ranged from 7 participants (qualitative study) to over 19000 participants for a large-scale epidemiological study. Four epidemiology studies did not present a sample size. All studies obtained ethics approval (online supplementary file 1).

Eighteen studies focused on children ( $0-18$ years) (table 1$)$, including six studies involving children and parents, and four studies of high-school students. Males were identified as being at greater risk than females in all studies except two; one presenting immersion-related injuries in Alaska ${ }^{22}$ and one analysing drowning among Aboriginal and Torres Strait Islander children in Australia. ${ }^{23}$

The literature was explored by characteristics of populations identified in the literature, risk factors identified for drowning among high-risk populations and prevention strategies for

\begin{tabular}{lcc}
\hline \multicolumn{2}{c}{ Table 1 Study design, country of study and population } \\
\hline \multicolumn{3}{l}{ N } \\
\hline Study design \\
$\quad$ Quantitative \\
$\quad$ Qualitative & 25 & 71.4 \\
\hline Mixed-method & 9 & 25.7 \\
\hline Total & 1 & 3.2 \\
\hline Country & 35 & 100.0 \\
\hline USA & & \\
\hline New Zealand & 20 & 57.1 \\
\hline Canada & 7 & 20.0 \\
\hline Australia & 4 & 11.4 \\
\hline Total & 4 & 11.4 \\
\hline Population studied & 35 & 100.0 \\
\hline Children (0-18years) & & \\
\hline Adults & 18 & 51.4 \\
\hline All ages & 10 & 28.6 \\
\hline Total & 7 & 20.0 \\
\hline
\end{tabular}

drowning identified in the literature. The findings will be presented under these headings.

\section{Characteristics of populations identified in the literature}

Four studies focused on Indigenous populations in Australia, and Canada as being of higher risk of drowning compared with nonIndigenous populations. ${ }^{23-25}$ Three identified migrant populations as being at increased risk of drowning compared with the general population in New Zealand, the USA and Canada. ${ }^{26-28}$ Two studies reported that minority populations residing in rural locations were at greater risk of drowning. ${ }^{23}{ }^{27}$ Ethnic-minority populations living in rural areas in Ontario, Canada, were found to have a higher age-adjusted drowning rate compared with people from European backgrounds and those living in urban areas. ${ }^{27}$ Another study reported higher rates of fatal drowning among Aboriginal and Torres Strait Islander children in rural locations in Queensland, Australia, compared with children living in urban locations. ${ }^{23}$

\section{Terminology relating to the identified high-risk populations}

When describing ethnic-minority populations in the literature, this review found over 20 different terms were used in the articles found. The description of ethnicity/race differed globally and within countries throughout the study period. For example, studies from the USA refer to both black and African-American and white or Caucasian. The authors recognise that while some of these terms are used interchangeably throughout the literature, some terms may be considered outdated or offensive. For consistency, the terms 'black' and 'white' as opposed to African-American and Caucasian have been used in this review ${ }^{13}$ (table 2).

Nine studies presented fatal or non-fatal drowning rates per population as a primary outcome, adjusted by age, gender and/ or ethnicity/race. ${ }^{8} 9222327$ 29-32 One presented fatal drowning rates of black children compared with white children as being $1.90 / 100000$ vs $1.32 / 100000$ (aged $0-30$ years). ${ }^{9}$ Another study reported higher rates of drowning in a swimming pool among black males compared with white males, with risk ratios ranging from 5.5 (5-9 years) to 12.1 (15-19 years). ${ }^{31}$ Drowning rates in Aboriginal and Torres Strait Islander children in Queensland, Australia were cited as $16.8 / 100000$ population or 1.44 times higher than non-Aboriginal children (0-19 years), with swimming pools cited as the leading location for drowning. ${ }^{23}$ Another study reported on the decline in drowning rates in Florida among black males from 15/100 000 in 1970 to less than four deaths per 100000 from 2005. ${ }^{32}$

Three US studies presented non-fatal drowning rates. ${ }^{8} 2229$ Drowning has three outcomes: death, residual morbidity and no morbidity. ${ }^{7}$ Therefore, non-fatal drowning is surviving a drowning event with or without long-term health consequences. One study reported the non-fatal drowning rate of black children (based on hospitalisation data) as being 17.7/100 000 compared with 4.3/100 000 for white children. ${ }^{8}$ The second presented an OR of 3.47 (1.24 to 9.75) for poor outcomes from a serious submersion (defined in the study as probability for chronic disability or death after submersion) among black children compared with white children (0-19 years). ${ }^{29}$ In contrast, one study from Alaska presented non-fatal drowning rates among ethnic-minority populations for children and adults, which found that females and those of white ethnicity were at increased risk of other injuries as a result of a non-fatal submersion incident. ${ }^{22}$ 
Table 2 Terms used in the literature to describe populations based on cultural and/or ethnic background

\begin{tabular}{|c|c|c|}
\hline Terms used in the literature & Country & Reference \\
\hline African-American/black: used interchangeably in the literature & USA & $929-343643-485053$ \\
\hline Culturally and linguistically diverse & $\begin{array}{l}\text { Australia } \\
\text { New Zealand }\end{array}$ & 26404152 \\
\hline Ethnicity & $\begin{array}{l}\text { New Zealand } \\
\text { Canada } \\
\text { USA }\end{array}$ & $825273237-39515362$ \\
\hline Ethnic minority also referred to as: minority ethnic groups & $\begin{array}{l}\text { USA } \\
\text { Canada } \\
\text { New Zealand }\end{array}$ & 273638444748 \\
\hline European ethnic groups: & USA & $8922-25293235-373942434547-495153$ \\
\hline White/Caucasian: used interchangeably in the literature & USA & \\
\hline Euro-Canadian & Canada & \\
\hline Euro-American & USA & \\
\hline New Zealand European & New Zealand & \\
\hline Non-Aboriginal/non-Indigenous & Canada, Australia & \\
\hline $\begin{array}{l}\text { Migrants: also referred to as: immigrants, new settlers/new arrivals } \\
\text { Country of origin, foreign-born }\end{array}$ & $\begin{array}{l}\text { NewZealand } \\
\text { Australia } \\
\text { Canada } \\
\text { USA }\end{array}$ & 262731475262 \\
\hline $\begin{array}{l}\text { Indigenous, also referred as: } \\
\text { Aboriginal } \\
\text { Native } \\
\text { First Nations } \\
\text { Aboriginal and Torres Strait Islander } \\
\text { Maori }\end{array}$ & $\begin{array}{l}\text { Canada } \\
\text { Australia } \\
\text { USA } \\
\text { New Zealand }\end{array}$ & $922263537-394243475162$ \\
\hline Multicultural, multiracial, multiethnic & $\begin{array}{l}\text { USA } \\
\text { New Zealand }\end{array}$ & $343742-4448$ \\
\hline Race & USA & 32334547 \\
\hline Racial identity (ethnicity) & USA & 9434448 \\
\hline
\end{tabular}

\section{Risk factors identified for drowning among high-risk populations}

Factors identified with drowning among high-risk populations were categorised into three subthemes: (a) social determinants, (b) attitudes and behaviour and (c) swimming ability and water safety knowledge (table 3).

\section{Determinants of health}

All studies identified ethnicity/race as a factor for increased drowning risk. Socioeconomic status and cultural beliefs were also identified as potential contributing factors for greater risk of drowning (table 3). Cultural beliefs included spiritual and religious reasons for avoiding water, as well as cultural practices around the water. Four articles cited the historical and political context of segregation in the USA, ${ }^{30} 313334$ and colonisation in Canada, ${ }^{35}$ as reasons for the present-day low levels of swimming participation and high drowning rates among the black population and Indigenous peoples of Canada (table 3).

\section{Behaviour and attitudes}

Common behaviour identified across all the identified populations for increasing drowning risk were reduced supervision (including of young children, swimming alone or at locations without lifeguards), ${ }^{36-38}$ alcohol consumption ${ }^{28} 363739$ and not wearing a lifejacket when boating or fishing. ${ }^{28} 3940$ Attitudinal factors cited included low levels of perception towards drowning risk, ${ }^{31} 3638394142$ parental influence and fear of water (parents and children). ${ }^{33} 3443-47$
Swimming ability and water safety knowledge

Fifteen articles cited poor/no swimming ability as increasing drowning risk. ${ }^{2426283032343637404547-49}$ Three studies measured swimming ability, ${ }^{46450}$ while 11 articles presented self-reported measures of swimming ability, including parental perception of their child's ability. ${ }^{26} 283437404849$ Six studies identified limited knowledge of water safety or drowning prevention practices. $^{2633} 36374151$ Two studies highlighted traditional water safety knowledge among First Nations/Aboriginal communities, such as wearing traditional clothing that floats and protects from cold water. ${ }^{2425}$

\section{Other factors}

Barriers to participation, such as lack of access to facilities and/ or programmes, and cultural appropriateness, ${ }^{2435} 4552$ as-well-as low frequency of participation and/or exposure, were considered factors for increasing drowning risk. ${ }^{303249} 53$ Levels of risk towards drowning differed by age and ethnicity in regard to locations; ranging from swimming pools to open water location and bathtubs. ${ }^{923} 25273142$

\section{Drowning prevention strategies}

Four articles reported on drowning prevention intervention studies. One from Canada, ${ }^{24}$ and one from Australia, ${ }^{52}$ reported on pilot programmes that modified existing aquatic programmes with the aim to increase diversity within the aquatic sector workforce, and to meet the cultural needs. The third was a learn-toswim programme targeted to Latino children aged 3-17 years, ${ }^{47}$ and the fourth was a long-term rock fishing safety campaign. ${ }^{39}$ 
Table 3 Drowning risk factors identified and described in the literature among high-risk populations

\begin{tabular}{|c|c|c|}
\hline Risk factor & Definition & Reference \\
\hline \multicolumn{3}{|l|}{ Determinants of health } \\
\hline Ethnicity & $\begin{array}{l}\text { The social group a person belongs to, and either identifies with } \\
\text { or is identified with by others, as a result of a mix of cultural } \\
\text { and other factors including language, diet, religion, ancestry and } \\
\text { physical features traditionally associated with race. }{ }^{9}\end{array}$ & $892236-4249515262$ \\
\hline Low socioeconomic status & $\begin{array}{l}\text { Usually determined by a government rank based on median } \\
\text { household or family income, generally classified as being of low } \\
\text { socioeconomic advantage. }\end{array}$ & 8233334363843454751 \\
\hline Cultural beliefs & $\begin{array}{l}\text { Different world views according to traditional customs and } \\
\text { knowledge that may influence attitudes, behaviours and } \\
\text { perception. Sometimes referred to as superstitions. }\end{array}$ & 2533365262 \\
\hline Age & Age of a person. & 822324862 \\
\hline Migrant & $\begin{array}{l}\text { Someone who has moved from one country to live in another } \\
\text { country, also referred to as immigrant. }\end{array}$ & 2628 \\
\hline Rurality of residential location & Geographical location based on remoteness to major services. & 232728 \\
\hline Cultural/Historical factors & $\begin{array}{l}\text { Cultural injustices that occurred in the past that have influenced } \\
\text { heath, education, social outcomes of populations today. }\end{array}$ & 30313335 \\
\hline Communication barriers/language & $\begin{array}{l}\text { Barriers in understanding language and communication between } \\
\text { two parties. }\end{array}$ & 2840 \\
\hline \multicolumn{3}{|l|}{ Attitudes and behaviour } \\
\hline Alcohol consumption & $\begin{array}{l}\text { Consuming an excess amount of alcohol, defined as blood alcohol } \\
\text { concentration } \leq 0.05 \% \text {. }\end{array}$ & 28363739 \\
\hline Reduced supervision & $\begin{array}{l}\text { Lack of adult supervision of young children, swimming alone, } \\
\text { swimming at unsupervised locations. }\end{array}$ & $36-38$ \\
\hline Risk perception of drowning & Considers the threat of drowning for themselves to be low risk. & 313638394142 \\
\hline Parental influence & $\begin{array}{l}\text { Influence of a parent's attitudes, knowledge and participation on } \\
\text { their child. }\end{array}$ & 33434446 \\
\hline Fear of water/drowning & Scared of the water, scared of the possibility of drowning. & 434550 \\
\hline Lack of wearing a lifejacket & Not wearing a lifejacket & 283940 \\
\hline \multicolumn{3}{|l|}{ Swimming ability and knowledge } \\
\hline Poor or no swimming skills & $\begin{array}{l}\text { Unable to perform swimming or survival skills to aid survival in an } \\
\text { emergency situation. }\end{array}$ & $2428303234-364045474851$ \\
\hline Poor water safety knowledge & $\begin{array}{l}\text { Very limited understanding and awareness of water safety } \\
\text { practices, making safety decisions and survival skills in regard to } \\
\text { drowning prevention. }\end{array}$ & 2633364151 \\
\hline Poor CPR knowledge and skills & $\begin{array}{l}\text { Very limited knowledge and understanding of how to administer } \\
\text { resuscitation effectively in an emergency situation. }\end{array}$ & 2651 \\
\hline Traditional water safety knowledge & $\begin{array}{l}\text { Traditional views of water safety and drowning risk based on } \\
\text { cultural perspectives. }\end{array}$ & 2425 \\
\hline
\end{tabular}

CPR, cardiopulmonary resuscitation.

\section{Proposed strategies}

Proposed strategies to reduce drowning among ethnic-minority populations were summarised into six categories: educationbased, practical programmes, community engagement, policy and research (table 4). Seven studies recommended generally 'targeting' or 'tailoring' culturally appropriate interventions to high-risk populations ${ }^{82325273549}$ (table 4).

\section{DISCUSSION}

This study found that ethnic-minority populations, including First Nations/Aboriginal peoples, migrants and those residing in rural locations were reported as being at greater risk for drowning. Determinants of health were identified as contributing factors for drowning across all populations. Only four papers explored evidence-informed, evaluated interventions targeting high-risk populations.

\section{Characteristics}

All studies identified ethnic-minority populations as being at increased risk of drowning compared with mainstream populations. Most studies referred to national-level drowning statistics stating that certain population groups presented higher numbers of drowning compared with others. ${ }^{8} 922313638-425153$ Indigenous populations were often combined into the 'ethnicminority' population category ${ }^{27}{ }^{48}$; however, prevention strategies are likely to be different due to the diverse underlying social determinants, including cultural beliefs. ${ }^{23} 2554$ This highlights the importance of understanding the specific characteristics of the target population.

\section{Migrants}

Migrants were considered to be at increased risk of drowning, due to unfamiliarity and unpreparedness towards their new geographical, social and cultural environment. ${ }^{26}$ It is difficult to ascertain level of risk due to the lack of exposure data, and is a gap in drowning prevention literature overall. Adult migrants may be more vulnerable to drowning compared with children as their newly adopted country will likely focus on swimming lessons for children rather than adults. ${ }^{2652}$ Shifting from a culture of using waterways for everyday life as opposed to recreation and leisure 


\begin{tabular}{|c|c|c|}
\hline Theme & Proposed prevention strategies/examples & Reference \\
\hline \multicolumn{3}{|l|}{ Education } \\
\hline Culturally appropriate & $\begin{array}{l}\text { Water safety education that incorporates cultural beliefs and practices and language (if required); } \\
\text { that is culturally appropriate and targeted to the population. }\end{array}$ & 263336374062 \\
\hline Information based & Education strategies in all forms of communication and is available in a range of languages. & 3951 \\
\hline Safe behaviour and decision making & $\begin{array}{l}\text { Water safety education focusing on safer behaviour and decision making around the water; that } \\
\text { promote accurate risk assessment and risk management. }\end{array}$ & $36-384042$ \\
\hline Of parents & $\begin{array}{l}\text { Water safety education for parents included with swimming lessons; to address fear of water and } \\
\text { drowning. }\end{array}$ & 434448 \\
\hline \multicolumn{3}{|l|}{ Engagement } \\
\hline Community engagement & $\begin{array}{l}\text { To recruit target populations to participate in swimming programmes; incorporation of traditional } \\
\text { knowledge and beliefs; establish an advisory group from the community being targeted; using a } \\
\text { 'cultural broker'. }\end{array}$ & 2533374153 \\
\hline Using cultural Brokers & Water safety education of parents within the healthcare setting. & 2833 \\
\hline \multicolumn{3}{|l|}{ Policy } \\
\hline Inclusion in school curriculum & Water safety education in the school curriculum mandated. & 26424351 \\
\hline Subsidised programme & $\begin{array}{l}\text { Offering free/low-cost swimming lessons, convenient locations; programmes subsidised for high- } \\
\text { risk populations. }\end{array}$ & 324851 \\
\hline Other & $\begin{array}{l}\text { Infrastructure: increase aquatic facilities in ethnic-minority communities, increased patrolled/ } \\
\text { lifeguarded locations, mandatory safety measures in place. }\end{array}$ & 324046 \\
\hline \multicolumn{3}{|l|}{ Practical strategies } \\
\hline Swimming lessons & $\begin{array}{l}\text { Swimming lessons targeting ethnic-minority populations; for all ages; single gender swimming } \\
\text { classes. }\end{array}$ & 294350 \\
\hline Water safety skills & Emphasis on water safety skills; targeted education campaigns focusing on water safety skills. & 25273653 \\
\hline CPR and first aid & Learning CPR. & 2629 \\
\hline \multicolumn{3}{|l|}{ Research themes } \\
\hline Evaluation & Evaluation of interventions and strategies targeting high-risk groups, and best practice models. & 232441484952 \\
\hline Social determinants & $\begin{array}{l}\text { Research of the broader socioeconomic factors and circumstances among high-risk populations, } \\
\text { cultural barriers influencing swimming participation. }\end{array}$ & 29314446 \\
\hline Disparities & Research to determine why disparities exist. & 30364448 \\
\hline Swimming skills & $\begin{array}{l}\text { Research investigating self-reported and actual swimming ability of children and adults; perceived } \\
\text { swimming and rescue competence matches real competence in the open water; retention of } \\
\text { swimming skills. }\end{array}$ & 34373847 \\
\hline \multicolumn{3}{|l|}{ Targeted strategies—general } \\
\hline Culturally appropriate interventions & $\begin{array}{l}\text { Culturally appropriate interventions (did not specify). } \\
\text { Targeting drowning prevention strategies towards ethnic-minority populations. }\end{array}$ & 82324273549 \\
\hline
\end{tabular}

CPR, cardiopulmonary resuscitation.

may be one reason for a lack of participation among adult migrants; however, this needs to be further explored. Reported participation in aquatic activity among adult migrants varied in the literature, with one study reporting an increased level postarrival in a new country, ${ }^{26}$ and another saying there was no difference (due to maintenance of spiritual beliefs). ${ }^{36}$ Priorities for new migrants are generally securing housing, employment and education ${ }^{55}$; therefore, learning to swim and participating in aquatic recreation is not often an immediate priority. A challenge for drowning prevention, and health promotion practitioners in general, is finding the best time/opportunity to offer/implement appropriate interventions, with readiness to participate likely to vary across different communities. ${ }^{556}$

\section{Rurality of residents}

Rurality has been linked to increased drowning risk, due to the abundance of natural waterways, remoteness from essential services and response time. ${ }^{57} \mathrm{~A}$ Canadian study included in this review reported that people of ethnic-minority backgrounds living in rural locations were more likely to drown, compared with people living urban locations. ${ }^{27}$ In high-income countries, new migrant and refugee communities are being settled in regional and rural locations, ${ }^{5558}$ which may exacerbate the threat of drowning among these populations. ${ }^{57}$ The challenge for drowning prevention and water safety advocates is to ensure that people are equipped with the knowledge and skills to live safely in their new community.

\section{Risk factors}

Factors identified in the literature as increasing drowning risk among the identified populations included social determinants of health, especially regarding cultural influences, historical factors and socioeconomic factors. These factors were found to influence attitudes, behaviour and participation.

\section{Determinants of health}

A lack of understanding exists about how social determinants interact with other factors such as swimming skills, knowledge, attitudes and behaviour. Socioeconomic status is commonly linked to affordability of swimming and water safety instruction, lifejackets and lower swimming ability. ${ }^{18} 33$ Lower levels of water safety skills, knowledge and participation rates were reported among ethnic-minority students attending schools in low socioeconomic areas. ${ }^{37} 51$ Research suggests that children of lower socioeconomic backgrounds are less likely to attend 
extracurricular activities, like swimming lessons, for reasons such as instruction cost and access to facilities. ${ }^{33}$ One solution commonly proposed to overcome these disparities was offering subsidised programmes. ${ }^{32} 4851$ However, the effectiveness of offering subsidised programmes to improve swimming skills and reduce drowning rates among high-risk populations is largely unknown. One method for accounting for social determinants of health in programme design is to incorporate health promotion frameworks that target both the downstream individual factors and at population level, from the upstream policy-driven approach. ${ }^{60}$ Drowning prevention practitioners should consider the determinants of health when developing and implementing interventions for all populations to enhance uptake and accessibility for those who are at greatest risk.

\section{Cultural bias}

Some cultural beliefs are considered protective towards drowning risk. One example cited in the literature reviewed, told of the legend 'Qallupilluit', a female sea monster of Indigenous Canadian myth told to children to prevent them from going near water. ${ }^{25}$ A study of Vietnamese-American parents reported their beliefs of ghosts in specific aquatic locations, and therefore avoided those environments. ${ }^{36}$ These findings are consistent with studies from low-income countries, such as China, where cultural beliefs of 'ghost month' (avoiding potentially life-threatening behaviours), appears to have reduced drowning deaths compared with other times of the year. ${ }^{61}$ In contrast, one study found from New Zealand indicated that the cultural practice of seafood gathering via diving and fishing activity has led to an increase in drowning deaths. ${ }^{62}$

In many cultures, particularly indigenous cultures, water holds significant importance, as a food source and a place of cultural and religious gatherings. ${ }^{54}$ However, the spiritual connection to water is rarely acknowledged in drowning prevention interventions targeting these populations. ${ }^{54}$ Present-day swimming programmes and aquatic venues are considered by some as being very Eurocentric, and may discourage people from attending programmes and aquatic facilities, driving people to swim in more hazardous, unsupervised environments. ${ }^{24} 254$ A proposed solution was providing cultural awareness training of aquatic industry staff, and recruiting staff reflective of the local communities, as evidenced in two studies included in the review. ${ }^{24} 52$

While the role of colonialism and segregation are sensitive and complex issues that illicit many opinions, for the purpose of this review, all social determinants of health that influence drowning outcomes were considered. The role of colonisation and intergenerational trauma is widely believed to have contributed to the racial disparities evident in drowning today, this has been shown to be in case in the USA ${ }^{3033}$ and Canada, ${ }^{2435}$ and is likely to apply in Australia ${ }^{54}$ and New Zealand.

The intergenerational fear of drowning among populations in the USA, along with the historical practices of certain population groups not being allowed to attend public swimming pools and swimming programmes, was explored in the literature. 30324353 Thus, addressing drowning rates and swimming and water safety education among these 'high-risk' populations is more complex than simply removing pragmatic barriers such as cost, transport or childcare, and requires further analysis which was beyond the scope of this study. Interestingly, one study reports that drowning disparities no longer exist between the black and white population in Florida due to a concerted effort from the 1970 s, to provide swimming lessons and promote competitive swimming to black children, despite Florida's segregation history. ${ }^{32}$ Strategies that work to reduce disparities and marginalisation of certain populations, such as in Florida, should be widely considered.

\section{Attitudes and behaviour}

Cultural beliefs can both positively and negatively influence risk perception. Several studies in this review implied that low levels of risk perception towards drowning puts an individual at greater risk, ${ }^{394042}$ as they may not fully understand the dangers and threat to their life. This has implications on communication and language when disseminating safety messages to communities. ${ }^{55}$ A parent's fear of water and drowning, their own swimming ability, cultural beliefs and encouragement towards learning swimming skills was found to influence their children's participation in aquatic activity, thus passing on their attitudes and beliefs to the next generation. ${ }^{334345}$ Opportunities to include the wider family and community in swimming and water safety programmes were proposed as a solution to influence these attitudes. ${ }^{29} 43444863$ The benefits of this approach are twofold: increasing the knowledge and skills of children and their parents, and introducing the health, well-being and social benefits that aquatic activity brings. To enable a greater understanding of attitudes and behaviour in relation to aquatic participation and perception of drowning risk, two studies applied the Protection Motivation Theory, ${ }^{39} 42$ and one used the Health Belief Model. ${ }^{47}$

\section{Swimming and water safety skills and knowledge}

The benefits of swimming and water safety skills, together with awareness of drowning risk, are well-established protective factors against drowning, ${ }^{7115}$ however, little is known about the aquatic skills and knowledge of adults from high-risk populations. Many people miss out on swimming and water safety education altogether, for example, adult migrants. ${ }^{26}{ }^{38}$ Swimming and water safety skills for adults is essential, given their responsibility of supervising children around water and the likelihood of being the first on scene in an emergency situation. ${ }^{57}$ The inclusion of cardiopulmonary resuscitation (CPR) and first-aid skills into water safety education was recommended. ${ }^{26} 29$ CPR is a vital factor in improving drowning survival rates, especially among young children. ${ }^{57}$ However, the cultural challenges of both teaching and performing CPR need to be acknowledged and discussed with high-risk populations.

\section{Prevention strategies for drowning identified in the literature}

Of the four intervention studies, only one explored the effectiveness of a prevention strategy to reduce drowning, targeting ethnic rock fishers. ${ }^{39}$ This study showed that a multifaceted campaign over sustained period influenced attitudes, knowledge and behaviour, leading to a reduced numbers of drowning deaths of rock fishers over the 10 -year study period. Two studies explored increasing qualified staff from within ethnic-minority populations; one pilot programme built community capacity via a swim teachers course adapted for people from minority backgrounds, ${ }^{52}$ and the other was an adapted lifeguard course to meet the needs of the local population and environment. ${ }^{24}$ The last study reported on increasing swimming skills among Latino children over an 8 -week programme. ${ }^{47}$ While all interventions intended to reduce drowning among these groups, the latter three were found to be effective only on intermediary outcomes (such as increased skills and knowledge), and did not report any impact on reducing drowning among the target population. $^{244752}$ 
Many recommendations proposed were general statements around the 'targeting', 'tailoring' or making interventions 'culturally appropriate' without providing specific examples of how this could be done. Incorporating cultural knowledge and traditional methods into interventions can be challenging, but nevertheless essential when developing strategies for culturally diverse populations. Public health approaches to drowning prevention often fail to incorporate the traditional knowledge and experience, and generally disregard this perspective. ${ }^{25}$ Using cultural brokers was proposed to (1) promote the value of swimming and water safety education to high-risk populations, and (2) as a way to build relationships between the community and practitioners to better understand and address the needs of the community. ${ }^{284}$

A challenge exists between modifying existing strategies to meet the needs of culturally diverse populations and maintaining the integrity of the programme, particularly if it leads to a formal qualification. Two studies ${ }^{24} 52$ adapted existing aquatic qualifications to meet the cultural and environmental needs of the target populations; however, both reported several challenges in the delivery, including condensing the programme while still incorporating the required material, translating resources and finding appropriate instructors to deliver in language. Measures of success included participants from both studies successfully completing and using their respective qualifications in the aquatic sector. ${ }^{2452}$

A wide range of prevention strategies were proposed, including: education (theoretical based and practical, such as swimming and water safety lessons), community engagement, policy and research. Further work is required to establish an evidence base for effectiveness of these strategies. At the policy level, incorporating swimming and water safety into the education curriculum may be beneficial for reaching children from high-risk populations. ${ }^{26374351}$ In theory, all children, regardless of ethnicity or socioeconomic background, would be taught swimming and water safety skills as part of their formal education. For example, road safety education has been successfully integrated in the primary school curriculum in Finland and Thailand, and could be used as a model for incorporating drowning prevention in the curriculum. ${ }^{6465}$ Further research and evaluation of such strategies should be considered to determine the effectiveness and impact of curriculum-based interventions at a population level.

\section{Frameworks used to explore high-risk drowning populations}

Eight studies were based on a framework or theoretical approach. ${ }^{2430} 333539424547$ Two studies used the Protection Motivation Theory, ${ }^{39}{ }^{42}$ and one applied the Health Belief Model. ${ }^{47}$ Five studies used social research theories such as the Leisure Constraints Model, ${ }^{33}$ ethnographically informed communitybased research, ${ }^{25}$ Lens of Critical Theory ${ }^{45}$ and a Foucauldian and postcolonial lens. ${ }^{35}$ One study applied a heuristic labour market model to hypothesise a link between drowning rates among African-Americans and competitive swimming participation rates. ${ }^{30}$ Generally, these studies used a model to frame either the methods or the results of the study rather than applying to the recommendations, to develop intervention studies. It is recommended that health promotion frameworks are used to guide drowning prevention interventions, rather than just the study itself, taking consideration of the complexity of the determinants of health to develop effective programmes. There is a need for robust evaluation studies that are based on sound theoretical frameworks to determine effectiveness and best practice in reducing drowning disparities for high-risk populations. To address this appropriately, future drowning prevention strategies should apply a health promotion approach that addresses upstream, midstream and downstream factors to drowning risk.

\section{Gaps in the literature}

There is a need for high-quality studies exploring drowning among adults from ethnic-minority populations. A recent review on evidence-based drowning interventions for adults (1990-2012) only found six studies (of which only one reported on cultural diversity), ${ }^{66}$ despite a trend in increased adult drowning. ${ }^{1162}$ This review highlights that drowning prevention targeting adults from high-risk populations should be prioritised at both the individual and population level.

The inconsistency of terminology when describing ethnicminority populations is challenging. No study provided a definition of who or what constitutes an 'ethnic minority', nor provided reasons for what makes these populations 'high-risk' for drowning. Further work around defining why a population is at greater risk for drowning is required. In some cases, ethnicity or cultural background may not be routinely collected at a national or regional level. In the absence of official ethnicity data in Canada, one study used name recognition software to allocate ethnicity based on census groupings, although the authors concede that some names, particularly of Indigenous/ Aboriginal origin, were unlikely to have been categorised accurately. ${ }^{27}$ Improved data collection of country of birth, ethnicity and/or cultural background and time in country by the relevant agencies would be beneficial to assist in determining populations at-risk, and planning appropriate interventions.

\section{Strengths and limitations}

The relevance of identifying minority populations ensures that the drowning prevention sector can respond appropriately, and effectively, to the diverse needs of all high-risk populations. This

\section{What is already known on the subject}

- Children are at high risk of drowning.

- Ninety per cent of drowning occurs in low-income and middle-income countries.

- High-risk populations such as ethnic minorities are overrepresented in injury statistics.

- Common risk factors for drowning overall include age, gender, environmental context, activity and alcohol consumption.

\section{What this study adds}

- Determinants of health, such as cultural background, influence drowning risk but are not well-understood and largely ignored when implementing prevention strategies.

- Health promotion frameworks should be considered when developing and implementing drowning prevention strategies for high-risk populations, to better understand attitudes and behaviour towards drowning risk.

- There is a need for high-quality studies exploring drowning among adults from high-risk populations, both at the individual and population level. 
review recognised that the social determinants of health influences drowning risk among these populations.

This review may have a publication bias, as articles were restricted to published, peer-reviewed articles in English between 1990 and 2018. Over half $(n=18)$ were published in the most recent 5-year period (2013-2018), indicating that this in an area of growing interest among drowning prevention researchers. While efforts were made to include all relevant studies, it is possible that some may have been missed. Inconsistency of definitions and terminology used in the literature also may have limited search results. Where drowning rates were provided, the differences of data sources used in the literature, between and within countries, made it challenging to compare studies and results.

\section{CONCLUSION}

Ethnic-minority populations are at increased risk of drowning. Addressing the determinants of health for drowning prevention is essential when developing and implementing strategies for high-risk populations, such as those from ethnic-minority populations. The determinants of health need to be considered at the individual and population level from both the upstream and downstream perspective, and incorporated into policy and practice to achieve meaningful change. Better understanding by drowning prevention practitioners as to the drivers underpinning vulnerability to drowning among these identified communities of higher risk is required.

Funding This research is supported by the Royal Life Saving Society—Australia to aid in the reduction of drowning. Research at the Royal Life Saving SocietyAustralia is supported by the Australian Government. Lead author SMW-P's doctoral studies are supported through an Australian Government Research Training Program Scholarship and the James Cook University Doctoral Research Cohort Program. Funding to publish this article open access was granted James Cook University Higher Degree Research Enhancement Scheme.

Competing interests None declared.

Patient consent for publication Not required.

Provenance and peer review Not commissioned; externally peer reviewed.

Open access This is an open access article distributed in accordance with the Creative Commons Attribution Non Commercial (CC BY-NC 4.0) license, which permits others to distribute, remix, adapt, build upon this work non-commercially, and license their derivative works on different terms, provided the original work is properly cited, appropriate credit is given, any changes made indicated, and the use is non-commercial. See: http://creativecommons.org/licenses/by-nc/4.0/.

\section{ORCID iDs}

Stacey M Willcox-Pidgeon http://orcid.org/0000-0003-0759-0675

Richard Charles Franklin http://orcid.org/0000-0003-1864-4552

Peter A Leggat https://orcid.org/0000-0002-8749-014X

\section{REFERENCES}

1 World Health Organization. Injuries and violence: the facts. Geneva, Switzerland: World Health Organization, 2014.

2 Commission on Social Determinants of Health. Closing the gap in a generation: health equity through action on the social determinants of health. Geneva: World Health Organisation, 2008.

3 Andermann A. Taking action on the social determinants of health in clinical practice: a framework for health professionals. Can Med Assoc J 2016;188:E474-83.

4 Giles AR, Brooks Cleator L, McGuire-Adams T, et al. Drowning in the Social Determinants of Health: Understanding Policy's Role in High Rates of Drowning in Aboriginal Communities in Canada. aboriginal policy studies 2014;3:198-213.

5 Steinbach R, Edwards P, Green J. Controlling for exposure changes the relationship between ethnicity, deprivation and injury: an observational study of child pedestrian injury rates in London. Inj Prev 2014;20:159-66.

6 Campos-Outcalt D, Bay C, Dellapena A, et al. Motor vehicle crash fatalities by race/ ethnicity in Arizona, 1990-96. Inj Prev 2003;9:251-6.

7 World Health Organization. Global report on drowning: preventing a leading killer. Geneva, Switzerland: World Health Organization, 2014
8 Felton $\mathrm{H}$, Myers J, Liu G, et al. Unintentional, non-fatal drowning of children: US trends and racial/ethnic disparities. BMJ Open 2015:5:e008444.

9 Gilchrist J, Parker EM, Centers for Disease Control and Prevention (CDC). Racial/ethnic disparities in fatal unintentional drowning among persons aged $\leq 29$ years - United States, 1999-2010. MMWR Morb Mortal Wkly Rep 2014;63:421-6.

10 Water safety New Zealand. New Zealand water safety sector strategy 2020. New Zealand: Water safety New Zealand, 2015.

11 Australian Water Safety Council. Australian water safety strategy 2016-20: towards a nation free from drowning (cumulative draft). Australian Water Safety Council, 2015: 48

12 Bhopal R. Glossary of terms relating to ethnicity and race: for reflection and debate. $J$ Epidemiol Community Health 2004; 58:441-5.

13 American Pyschological Association (APA). Racial and ethnic identity, 2019. Available: https://apastyle.apa.org/style-grammar-guidelines/bias-free-language/racial-ethnicminorities [Accessed 01 Nov 2019].

14 International Organization for Migration. International migration law: glossary on migration. International organization. Geneva: for Migration, 2019.

15 Wallis BA, Watt K, Franklin RC, et al. Interventions associated with drowning prevention in children and adolescents: systematic literature review. Inj Prev 2015;21:195-204

16 Crawford G, Leavy J, Portsmouth L, et al. Development of a systematic review of public health interventions to prevent children drowning. Open J Prev Med 2014;04:100-6.

17 Hamilton K, Schmidt H. Critical beliefs underlying young australian males' intentions to engage in drinking and swimming. Sage Open 2013;3.

18 Moran K, Podstawski R, Mańkowski S, et al. Socioeconomics influences on the water competencies of young adult Polish males. Physical Culture and Sport Studies and Research 2017;74:19-33.

19 Law M, Stewart D, Pollock N, et al. Critical review form - quantitative studies. McMaster University, ND.

20 Letts L, Wilkins S, Law M, et al. Critical Review Form - Qualitative Studies (Version 2.0). McMaster University, 2004.

21 Braun V, Clarke V. Using thematic analysis in psychology. Qual Res Psychol 2006:3:77-101.

22 Hudson DS, Nilsen P, Johnson JS, et al. Hospitalizations for immersion-related injuries in Alaska 1991-2000. Saf Sci 2006:44:479-89.

23 Wallis BA, Watt K, Franklin RC, et al. Drowning in Aboriginal and Torres Strait Islander children and adolescents in Queensland (Australia). BMC Public Health 2015; 15:795.

24 Giles AR, Rich KA. Contextually appropriate aquatic programming in Canada's North: the shallow water pool lifeguard certification. The Canadian Journal of Native Studies 2013:33:49-64.

25 Giles AR, Castleden H, Baker AC. "We listen to our Elders. You live longer that way": examining aquatic risk communication and water safety practices in Canada's North. Health Place 2010;16:1-9.

26 Moran K, Wilcox S. Water Safety Practices and Perceptions fo "New" New Zealanders International Journal of Aquatic Research and Education 2013;7:136-46.

27 Gallinger ZR, Fralick M, Hwang SW. Ethnic differences in drowning rates in Ontario, Canada. J Immigrant Minority Health 2015:17:1436-43.

28 Arcury TA, Quandt SA, Elmore RC, et al. Water safety among Latino farmworkers in North Carolina. J Agromedicine 2002;8:77-83.

29 Lee LK, Mao C, Thompson KM. Demographic factors and their association with outcomes in pediatric submersion injury. Acad Emerg Med 2006;13:308-13.

30 Myers SL, Cuesta A, Lai Y. Competitive swimming and racial disparities in drowning. Rev Black Polit Econ 2017:44:77-97.

31 Saluja G, Brenner RA, Trumble AC, et al. Swimming pool drownings among US residents aged 5-24 years: understanding racial/ethnic disparities. Am J Public Health 2006:96:728-33

32 Gorsuch MM, Myers SL, Lai Y, et al. Vanishing racial disparities in drowning in Florida. Inj Prev 2018:23

33 Ross SR, Irwin CC, Irwin RL, et al. The development of swimming skills for African American youth: parent and caregiver perceptions of barriers and motivations. International Journal of Aquatic Research and Education 2014;8:219-39.

34 Siano CJ, Messiah SE, Banan L, et al. Swimming proficiency in a multiethnic sample in a high-risk area for drowning. Arch Pediatr Adolesc Med 2010;164:299-300.

35 Rousell DD, Giles AR. Leadership, power and racism: lifeguards' influences on Aboriginal people's experiences at a Northern Canadian aquatic facility. Leisure Studies 2012;31:409-28.

36 Quan L, Crispin B, Bennett E, et al. Beliefs and practices to prevent drowning among Vietnamese-American adolescents and parents. Inj Prev 2006;12:427-9.

37 Pidgeon-Willcox SM, Kool B, Moran K. Knowledge, attitudes, and behaviours of new Zealand youth in surf beach environments. International Journal of Aquatic Research and Education 2017;10.

38 Stanley T, Moran K. Self-Estimates of swimming and rescue competence, and the perceptions of the risk of drowning among minority groups in New Zealand - life saving or life threatening? Journal of Education and Human Development 2018;7:82-91

39 Moran K. Rock-based Fisher safety promotion: a decade on. International Journal of Aquatic Research and Education 2017;10. 
40 Jasper R, Stewart BA, Knight A. Behaviours and attitudes of recreational fishers toward safety at a 'blackspot' for fishing fatalities in Western Australia. Health Promot J Austr 2017;28:156-9.

41 Mitchell R, Haddrill K. Working in partnership with the Chinese community in NSW to develop appropriate strategies to target water safety. Health Promot J Austr 2004;15:38-43.

42 Willcox-Pidgeon S, Kool B, Moran K. Perceptions of the risk of drowning at surf beaches among New Zealand youth. Int J Inj Contr Saf Promot 2018:25:365-71.

43 Irwin CC, Irwin RL, Ryan TD, et al. The legacy of fear: is fear impacting fatal and nonfatal drowning of African American children? J Black Stud 2011;42:561-76.

44 Irwin CC, Irwin RL, Ryan TD, et al. The mythology of swimming: are myths impacting minority youth participation? International Journal of Aquatic Research and Education 2009;3:10-23.

45 Ito GH. Barriers to swimming and water safety education for African Americans. International Journal of Aquatic Research and Education 2014:8:240-57.

46 Mael FA. Staying afloat: Within-group swimming proficiency for whites and blacks. J Appl Psychol 1995;80:479-90.

47 Olaisen RH, Flocke S, Love T. Learning to swim: role of gender, age and practice in Latino children, ages 3-14. Inj Prev 2018;24:129-34.

48 Irwin CC, Irwin RL, Ryan TD, et al. Urban minority youth swimming (in)ability in the United States and associated demographic characteristics: toward a drowning prevention plan. Inj Prev 2009;15:234-9.

49 Fife D, Goldoft M. Swimming capabilities and swimming exposure of new Jersey children. J Safety Res 1994;25:159-65.

50 Berukoff KD, Hill GM. A study of factors that influence the swimming performance of Hispanic high school students. International Journal of Aquatic Research and Education 2010;4.

51 Moran K. Will they sink or swim? New Zealand youth water safety knowledge and skills. International Journal of Aquatic Research and Education 2008;2:114-27.

52 Savage MA, Franklin RC. Exploring the delivery of swimming and water safety teacher training to culturally and linguistically diverse communities. International Journal of Aquatic Research and Education 2015;9:241-56.

53 Hastings DW, Zahran S, Cable S. Drowning in inequalities: swimming and social justice. J Black Stud 2006;36:894-917.
54 Stronach MAS, Maxwell H. 'Djabooly-djabooly: why don't they swim?": the ebb and flow of water in the lives of Australian Aboriginal women. Annal of Leisure Resesarch 2018 (published Online First: 24 July 2018).

55 Hanson-Easey S, Every D, Hansen A, et al. Risk communication for new and emerging communities: the contingent role of social capital. International Journal of Disaster Risk Reduction 2018;28:620-8.

56 Clifford KM, Brander RW, Trimble S, et al. Beach safety knowledge of visiting International study abroad students to Australia. Tourism Management 2018;69:487-97.

57 Peden AE, Franklin RC, Leggat PA. Cardiopulmonary resuscitation and first-aid training of river users in Australia: a strategy for reducing drowning. Health Promot J Austr 2019;30:258-62.

58 Schech S. Silent bargain or rural cosmopolitanism? refugee settlement in regional Australia. J Ethn Migr Stud 2014;40:601-18.

59 Whyte Z, Larsen BR, Fog Olwig K. New neighbours in a time of change: local pragmatics and the perception of asylum centres in rural Denmark. J Ethn Migr Stud 2019;45:1953-69.

60 Talbot LVG. Promoting health: the primary health care approach. 5th edn. Chatswood, New South Wales: Elsevier Australia, 2014

61 Yang $\mathrm{C}-\mathrm{H}$, Huang Y-T, Janes $\mathrm{C}$, et al. Belief in ghost month can help prevent drowning deaths: a natural experiment on the effects of cultural beliefs on risky behaviours. Soc Sci Med 2008;66:1990-8.

62 Croft JL, Button C. Interacting factors associated with adult male drowning in New Zealand. PLoS One 2015;10:e0130545.

63 Jacobs TJ. Minority children swimming instruction participation: a single case study. Northcentral University, 2017.

64 Jamjuree D, Srathongphun S. Lessons learned from conducting road safety curriculum in Thai schools. world injury prevention conference Finland. Inj Prev2016.

65 Tuomikoski S L. Traffic safety education: its support in the curriculum, culture and work of schools in Finland. world safety and injury prevention conference Finland. Injury Prevention 2016.

66 Leavy JE, Crawford G, Portsmouth L, et al. Recreational drowning prevention interventions for adults, 1990-2012: a review. J Community Health 2015;40:725-35. 